\title{
A Framework for Traceable and Transparent Supply Chain Management for Agri-food Sector in Malaysia using Blockchain Technology
}

\author{
Kok Yong Chan ${ }^{1}$, Johari Abdullah ${ }^{2}$, Adnan Shahid Khan ${ }^{3}$ \\ Faculty of Computer Science and Information Technology \\ Universiti Malaysia Sarawak, Kota Samarahan, Malaysia
}

\begin{abstract}
This paper presents a framework for traceable and transparent supply chain management (SCM) system for the agri-food sector using blockchain technology in Malaysia. Numerous researchers believed that the current SCM system consists of several weak points, especially when multiple enterprise resource planning (ERP) system utilizing centralized SCM. Thus, data transparency and traceability are limited. This study hypothesized that if blockchain technology correlates with transparency and traceability of SCM, the above limitation can be minimized, as blockchain technology works in a distributed manner. This research uses "pepper" as an agri-food domain. The research also recommends that permissioned blockchain is a better fit as compared to permissionless blockchain.
\end{abstract}

Keywords-Supply chain; blockchain; consensus algorithm; traceability; transparency

\section{INTRODUCTION}

Supply chains are essentially a series of linked suppliers and customers until products reach the ultimate customer [1]. A good supply chain management should have a high degree of traceability and transparency. Transparency of a supply chain is the extent to which all its stakeholders have a shared understanding and access to the product-related information that request without loss, noise, delay and distortion [2]. Aung and Chang define traceability in terms of what, how, where, why and when aspects of underlying product along a supply chain [3]. Other than managing food quality and safety risks, an effective food traceability system also promotes the development of effective Food Supply Chain management [4]. In recent years, the supply chain industry shows some interest in blockchain technology and some suggest that it might have certain positive impact on the traceability and transparency of supply chain management.

Blockchain is a shared and distributed ledger that used to store transaction records in a business network [5]. Every record stored in the blockchain is automatically encrypted and is decentralized and trackable; hence it meets the requirement of a transaction which is fast and secure. There are a few characteristics in a blockchain network. First is consensus, all parties in the blockchain network must follow a certain protocol to validate a transaction. Second is provenance, the source of information of transaction in a blockchain network is trackable. The third is immutability, there is no chance that a participant in a blockchain network can tamper the information of a transaction when it is recorded and stored in the blockchain. Its usage is best known as the backbone of Bitcoin which is currently one of the most popular cryptocurrencies. However, the ability of blockchain is far beyond the creation of cryptocurrency. Theoretically it can be applied to supply chain management to overcome certain issues.

The business of the agri-food sector, also known as agribusiness, is one of the most important economic sectors in Malaysia, Koo, Othman, Moy, and Khor said that it contributed around 8.6 percent of Gross Domestic Product [6]. Pepper as one of the agri-food in Malaysia, known as the king of Spices, has been exported 12,199mt of pepper worth RM490.2mil to Japan, China, Hong Kong, South Korea, Taiwan, and Singapore in 2016 [7].

However, such a large economy contributor is facing certain challenges. Fletcher reported that up to one hectare of land in the Samunsam Wildlife Sanctuary Sarawak, which is near the border with the Camar Bulan village at West Kalimantan, has been turned into pepper farms by the Indonesians who live there [8]. Mah mentioned that rural pepper farmers from Sarawak still depend on this crop as their main source of income [7]. In Malaysia, the pepper industry has provided employment and income for about 67,000 farming families and households. This incident is highlighting the importance of traceability and transparency in supply chain management to ensure that all production of agri-food is from valid and authorized sources as it is a matter for both the income of the farmer and economy of the country.

\section{A. Problem Statement}

The background of the study reflects how important the agribusiness sector is playing the role in the economy of Malaysia. As for that, it is important for us to identify the business friction that impedes the productivity of agribusiness. Improvement of the supply chain is one of the suggestions that could overcome the business friction experienced by the agribusiness industry.

Conventional software solution used in industry is in a centralized model as well as supply chain management solution. With conventional methods for recording transactions and tracking assets, participants on a network keep each own ledgers and other records [5]. This could cause information friction that results in imperfect information and information risks. Imperfect information exists when all the parties in the business network do not have access to the same information 
as each of the party is having each own copy of information. This is where the missing of transparency in supply chain management as the information altered accidentally or purposely without acknowledgment of relevant party in the supply chain network.

Most of the existing solutions possess strong traceability, but almost neglect transparency of supply chain management. This lack of transparency is often intentional as some participants want to keep the competitive advantages from other competitors such as an inexpensive supplier who delivers quality products on time. This also implies another issue that its scale may lead to delays and defaults in the delivery of goods [9].

\section{B. Objective}

The aim of this research is to design and develop a framework for traceable and transparent supply chain management solution for the agri-food sector in Malaysia using blockchain technology.

Other objectives include:

- To study which kind of blockchain is more suitable to apply to the selected case study (agri-food supply chain)

- To find out how blockchain technology correlates with traceability and transparency of the supply chain.

\section{Scope}

Blockchain technology remains in infancy, but it is gaining momentum within supply chains, trust being the predominant factor driving adoption. The value of such technologies for supply chain management lies in four areas: transparency, traceability, supply chain digitalization and disintermediation, improved data security and smart contracts [10]. This study will focus on the first two areas which are transparency and traceability.

Other than that, the exploration of blockchain for the purpose of this study will also an emphasis on permissioned or private blockchain technology Hyperledger. Although there might some other private blockchain platform other than Hyperledger, this will just adopt Hyperledger for the solution since the whole point of the research is to compare private and public blockchain platforms and not among private blockchain platforms.

From the domain of supply chain management, this study will focus on the supply chain process of the agri-food sector which is pepper. The environment for implementation and testing the solution will model this supply chain process as much as possible based on the information gathered.

\section{LITERATURE REVIEW}

Supply chain management is an important piece of enterprise resource planning (ERP). Supply chain management is the oversight of funds, raw materials, components, and finished products, as these items move from suppliers to manufacturers, to wholesalers, to retailers, to consumers. The figure below illustrates the overview of supply chain management of agri-food (pepper) in Malaysia.
Based on Fig. 1, each participant in the supply chain network is linked together with a physical flow of certain products. The whole network of supply chain network of agrifood consists of 5 participants. The role of the farmer is most understandable, which include in charge of farming, harvesting the product and send to the processor. Processor role could be varied depends on the type of food or product in the supply chain network. For instance, the product of pepper will undergo the process of fermentation, washing, drying, and grinding. Once these processes are done, it will be packaged and certified by JAKIM for the halal certificate. The next participant in the supply chain network is distributor, who in charge of storage and warehousing of all the packaged product to be distributed to retailer, wholesaler or other channels so that product is available for the consumer.

The representation of the supply chain management from Fig. 2 seems a simple process however a comprehensive of logistic take place behind the scene when a product flow from one party to another party. Take example of farmer transfers harvested crops to a processor.

In real-world scenario, it usually involved another participant (a middleman) in the supply chain network known as a trusted third-party logistic provider as shown in Fig. 2. According to Chetak Logistic first party logistic (1PL) is referring a firm to make certain shipments from location A to location B by the firm itself; the firm itself has control of all the logistic processes [11]. Second party logistic (2PL) refers to a firm rent the transportation service from a service provider to get the shipment done, while the firm still has control of all the logistic processes. Third party logistic (3PL) is a firm outsource part or all the logistic work to a service provider. One of the roles of 3PL that distinguish itself from 2PL and 1PL is facilitating trust in the supply chain process such as certifying raw materials, components, or finished products, as these items travel through the supply chain. The reason for 3PL is involved in the supply chain network is due to systems operating in a centralized model, where all transactions are executed through a trust-based system making all participants dependent on the third party [12]. The implication of the modern systems operating in a centralized model is that the execution of transactions is dependent on a third party i.e. both the supplier and consumer rely on the third party for the exchange of goods or services [13].

Laney (2018) point out that the current supply chain management system consists of a certain weak point [14]. These weak points happen when there is multiple enterprise resource planning (ERP) systems in use across different organizations as data does not flow well via interface points between systems or individual ledgers during the transference of ownership or change in status between two parties. Thus, data transparency is limited at the hand-off points of raw materials, components, funds, and finished products.

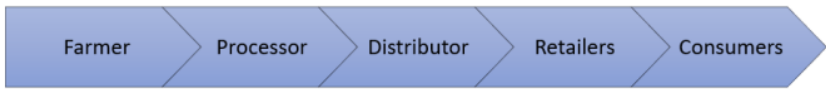

Fig. 1. A Typical Supply Chain in the Retail Industry in Malaysia. 


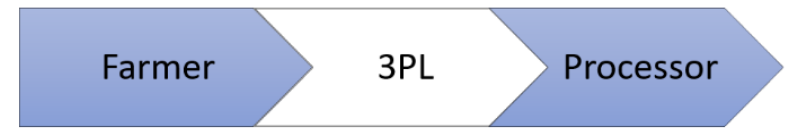

Fig. 2. Third Party Logistic (3PL).

\section{A. Supply Chain Transparency and Traceability}

Traceability and transparency are often used as interchangeable terms during the discussion of supply chain management. In order to develop a useful solution for supply chain management, it is important to find out differences between these terms as both of it is two different indicator of a good supply chain management system. The detailed concept of transparency can be visualized in Fig. 3 .

Transparency has been defined as the disclosure of information [15] that enables fair competition [16], profitable business ventures [17], and company fulfillment regarding sustainability efforts [18]. According to Tsai, supply chain transparency captures high-level information about a supply chain a product such as product components, names of suppliers, locations, associated certifications, etc. [19].

In other words, transparency decides the breadth of the information or disclosure of information that can be exposed to a certain party. Based on Fig. 4, supply chain transparency enables participants to identify all the suppliers for all the components in a product, down to the provenance. Supply chain transparency also enables participants in the supply chain network to identify and collect previously unknown product information and/or communicate and establish specific requirements. Thus, all the participants can gain better visibility of their global supply chains and ensure compliance with safety, sustainability, and social responsibility requirements.

Tsai mentioned that supply chain traceability captures much more granular information about a product component, such as batch-lot data (harvest date, field data, etc.), purchase order data, and other operational information [19]. Unlike supply chain transparency, the focus of traceability is less on mapping the entire end-to-end supply chain but on following the flow of product components or purchase orders as it moves through the supply chain. The granularity of the data used in traceability allows more targeted recalls, reducing scale and cost.

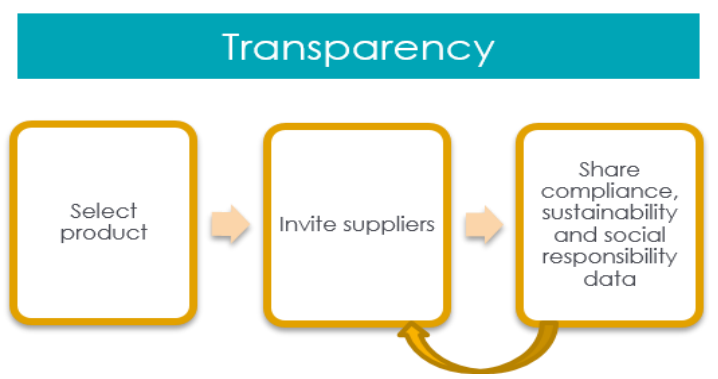

Fig. 3. Supply Chain Transparency

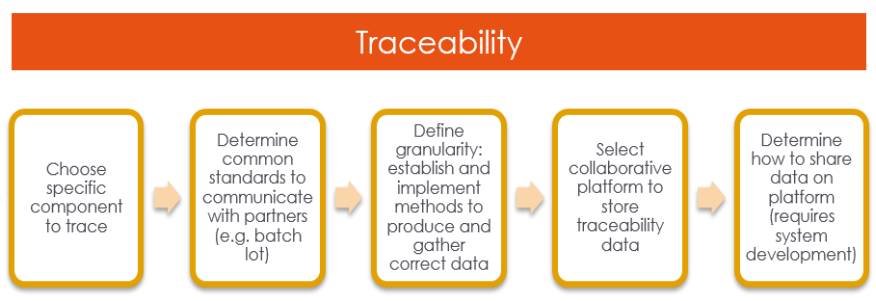

Fig. 4. Supply Chain Traceability.

Fig. 5 depicts the relationship between supply chain transparency and traceability that is traceability relies on transparency [19]. Transparency must come first before traceability data can be collected. Without transparency, it is not practical to implement traceability. For example, granular information such as batch, operational data, purchase order data is almost impossible to gather without information of the supplier. Successful supply chain management requires traceability that is built upon complete transparency.

\section{B. Blockchain}

According to Hyperledger, a blockchain is a peer-to-peer distributed ledger forged by consensus, combined with a system for "smart contracts" and other assistive technologies [19]. Blockchain can be categorized as public blockchain and private blockchain, due to these difference public blockchain and private blockchain operate under different consensus algorithms for different purposes.

1) Public Blockchain vs Private Blockchain: In public blockchains (permissionless) anyone can join as regular user or miner. All participants can perform transactions or operate under conditions preset in smart contracts [20]. Bitcoin is the pioneer of the public blockchain platform. It's the first cryptocurrency unveiled using blockchain as the backbone of the infrastructure to store transaction data in an untampered manner with the hash algorithm make it even more secure. A public blockchain network like bitcoin is accessible to anyone around the globe, anyone can make transactions with Bitcoin and anyone could be the miner in the bitcoin blockchain network under the Proof of Work consensus protocol. Miners are those who verify the new transaction and create the new block [21].

Ethereum is the most popular blockchain alternative of Bitcoin which borrows heavily from the Bitcoin architecture. It is a public blockchain with a built-in cryptocurrency called Ether. What distinguishes Ethereum from Bitcoin is that Ethereum is an open source platform that enables developers to build and deploy decentralized applications (dApps). On the other hand, Ethereum has smart contracts that define rules and penalties around an agreement and also enforces those obligations. The role of the smart contract is to keep conditional records and upon occurring specific events [22]. The smart contract allows the performance of transactions without involving any third parties [23]. 
Transparency

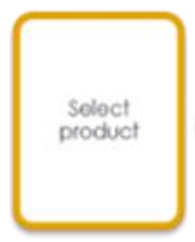

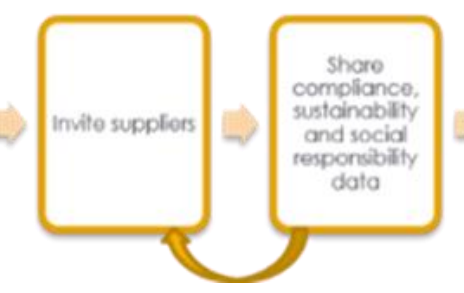
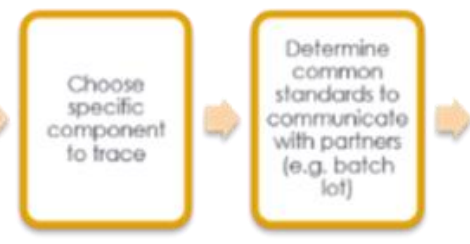

Traceability

Fig. 5. Supply Chain Transparency and Traceability.

Instructions embedded in Ethereum contracts are paid for in ether (or more technically "gas") and can be implemented in a variety of scripting languages. Ethereum currently uses a proof of work (PoW) protocol but the plan is to update its network to proof of stake (PoS). In a subset of nodes from the Ethereum network, the winner from the miners validates and appends the new block in their ledger and broadcast it to other nodes [24]. Ethereum provides a cryptocurrency called Ether, which can be transferred between accounts and used as reward for miner who successfully approves the transaction [25].

Permissioned blockchain only allows authorized nodes that are pre-registered by authorities to join the blockchain network [26]. Hyperledger Fabric is a permissioned blockchain infrastructure providing a modular architecture with a delineation of roles between the nodes in the infrastructure, execution of Smart Contracts and configurable consensus and membership services. Consensus is optional for Hyperledger Fabric depending application specific requirements various algorithms can be used hence no mining is required.

The most essential distinction between Hyperledger and Ethereum is the intent of both technologies is designed for (see Fig. 6). Ethereum runs the Smart Contracts on the EVM for applications that are attributed to being decentralized and are for mass consumption. On the other hand, Hyperledger leverages blockchain technology for business. It is designed to support pluggable implementations of components delivering high degrees of confidentiality, resilience, and scalability. Hyperledger has a modular architecture and provides a lot of flexibility in how you want to use it. Its extensible architecture provides futuristic solutions for enterprise blockchains.

2) Hyperledger: Hyperledger is an open source collaborative effort created to advance cross-industry blockchain technologies. It is a global collaboration, hosted by The Linux Foundation, including leaders in finance, banking, Internet of Things, supply chains, manufacturing and Technology [27].

There are currently five blockchain frameworks under the umbrella of Hyperledger, which are Fabric, Sawtooth, Iroha, Indy, and Burrow. Each of these frameworks established at different time and has unique features of its own. Among them Fabric is the earliest and most mature framework when comes to stability and popularity adoption, Sawtooth comes close to Fabric as second most mature, the rest of it still under the incubation stage.
In the exploration of Hyperledger Fabric and Hyperledger Sawtooth, there are a few key differences that are clarified in Table I which are used as references to determine which of it is best adopted for the framework in this study.

Both consensus algorithm of the framework has its own built-in consensus algorithm. Fabric is using Kafka, which is one kind of crash fault tolerant, but it does not prevent the system from reaching an agreement in the case of malicious or faulty nodes like Byzantine Fault Tolerant (BFT). Sawtooth is using Proof of Elapsed Time (PoET), each of the node that involved in approving the transaction is randomly given a waiting time, the node that with the shortest waiting time will be the one that approves the transaction.

\begin{tabular}{|c|c|c|}
\hline Characteristics & Ethereum & Hyperledger Fabric \\
\hline Founded Date & July 2015 & July 2017 \\
\hline Currency & Ether & None \\
\hline Governance & $\begin{array}{l}\text { Ethereum Developers } \\
\text { Enterprise Ethereum Alliance }\end{array}$ & $\begin{array}{l}\text { Linux Foundation } \\
\text { IBM }\end{array}$ \\
\hline Consensus & POW (Proof of Work) & $\begin{array}{l}\text { No-op (no consensus needed) } \\
\text { PBFT (Practical Byzantine Fault } \\
\text { Tolerance) }\end{array}$ \\
\hline Network & $\begin{array}{l}\text { Permissionless, Public or } \\
\text { Private }\end{array}$ & Permissioned, Private \\
\hline
\end{tabular}

Fig. 6. Ethereum vs Hyperledger Fabric (Melissa, 2017).

TABLE. I. DIFFERENCES OF HYPERLEDGER FABRIC AND HYPERLEDGER SAWTOOTH

\begin{tabular}{|l|l|l|}
\hline $\begin{array}{l}\text { Differences of } \\
\text { components }\end{array}$ & Hyperledger Fabric & Hyperledger Sawtooth \\
\hline $\begin{array}{l}\text { Consensus } \\
\text { algorithm }\end{array}$ & Kafka & $\begin{array}{l}\text { Proof of Elapsed Time } \\
\text { (PoET) }\end{array}$ \\
\hline $\begin{array}{l}\text { Network } \\
\text { Infrastructure }\end{array}$ & Permissioned & $\begin{array}{l}\text { Permissioned or } \\
\text { Permissionless }\end{array}$ \\
\hline Governance & $\begin{array}{l}\text { More restricted with } \\
\text { Membership Service } \\
\text { Provider (MSP) feature }\end{array}$ & $\begin{array}{l}\text { More open approach on } \\
\text { adding roles to the } \\
\text { network }\end{array}$ \\
\hline Transparency & $\begin{array}{l}\text { Comes with "Channel" } \\
\text { feature that only show } \\
\text { related ledger } \\
\text { (information) to relevant } \\
\text { party in the network }\end{array}$ & $\begin{array}{l}\text { All the party in the } \\
\text { network has read access } \\
\text { to all the ledger in the } \\
\text { joined network }\end{array}$ \\
\hline
\end{tabular}


One of the unique infrastructure characteristics of Sawtooth is the network can be permissioned or permissionless. Hence Sawtooth has a flexible approach using roles and permissions. Fabric has a built-in Membership Service Provider (MSP) feature which promotes better governance than Sawtooth. Any party has to undergo MSP system for identity verification to join the network. A digital certificate will be issued to each of them for further verification to perform every transaction.

Fabric has a feature, "Channel" which serves the purpose of organizing the information in need to know basis. With Channel, only related ledger is appending on the relevant parties.

\section{Related Works of Blockchain on Supply Chain}

Blockchain is believed being able to solve the weak points of current supply chain management by eliminating the need for a 3PL to account for transactions and good among other data or at least reduce its role to $2 \mathrm{PL}$ or 1PL because all participants have access of untampered past transactions in the blockchain network. From recent literature, there are a few approaches to apply blockchain technology on the supply chain as shown as Table II.

Most of the solutions adopted on the above studies use public blockchain (i.e. Ethereum) solutions that are permissionless blockchain. Some other solution is just merely determining the feasibility or potential of applying blockchain technology on supply chain rather than provide a usable solution for the supply chain management. There is more similar research have been done but most of it also consists of the mentioned research gap hence only some of the research without showing redundant information

TABLE. II. RELATED WORKS OF BLOCKCHAIN ON SUPPLY CHAIN

\begin{tabular}{|l|l|}
\hline Researches & Research Gap \\
\hline $\begin{array}{l}\text { Blockchain for securing } \\
\text { sustainable transport contracts } \\
\text { and supply chain transparency }\end{array}$ & $\begin{array}{c}\text { - The solution is merely to explore the } \\
\text { potential of blockchain in providing } \\
\text { transparency to supply chain system }\end{array}$ \\
\hline $\begin{array}{l}\text { Blockchain Technology in Supply } \\
\text { Chain Traceability Systems } \\
\text { Eveloping a Framework for }\end{array}$ & $\begin{array}{l}\text { - This solution is aimed to improve } \\
\text { traceability of a supply chain } \\
\text { management and neglect transparency }\end{array}$ \\
$\begin{array}{l}\text { - The solution is just to determine the } \\
\text { applicability of blockchain in the } \\
\text { supply chain and not providing an end } \\
\text { solution }\end{array}$ \\
\hline $\begin{array}{l}\text { The Supply Chain Has No } \\
\text { Clothes: Technology Adoption of } \\
\text { Blockchain for Supply Chain } \\
\text { Transparency }\end{array}$ & $\begin{array}{l}\text { - The solution is merely used to predict } \\
\text { the usefulness or feasibility or } \\
\text { blockchain with supply chain }\end{array}$ \\
\hline $\begin{array}{l}\text { Blockchains Everywhere - A Use- } \\
\text { case of Blockchains in the } \\
\text { Pharma Supply-Chain }\end{array}$ & $\begin{array}{l}\text { - modium.io built on top of Ethereum } \\
\text { which is a public blockchain network }\end{array}$ \\
\hline $\begin{array}{l}\text { Towards an Ontology-Driven } \\
\text { Blockchain Design for Supply } \\
\text { Chain Provenance }\end{array}$ & $\begin{array}{l}\text { - Solution built on top of Ethereum } \\
\text { public blockchain network } \\
\text { Data is visible to the public }\end{array}$ \\
\hline
\end{tabular}

\section{FRAMEWORK}

\section{A. Introduction on Conceptual Framework}

The conceptual framework will comprise of a supply chain system using blockchain and all the relevant parties (i.e. farmer, processor, distributor, retailer, and consumer) in the supply chain join in the network. The supply chain system will be given a code name "Prochain". Prochain is a traceable and transparent supply chain system that builds on top of the blockchain that will cover the whole process of data management, such as data input, sharing and data monitoring of every activity in the supply chain network. Prochain allows these verified parties to have write access to create a transaction with each other and gain read access for the information whenever needed. Prochain is illustrated in Fig. 7.

Prochain consists of components like identity verification, consensus algorithm, and database. Prochain will first assign a digital certificate to each of the parties that are to be invited to join the supply chain network, this means that all the parties in Fig. 7 like farmer, processor, distributor, retailer will be issued a digital certificate to each of them. It is required for identity verification when needed to have write access to create transaction to other party. Prochain could allow second the party join the network if the party within the blockchain network agreed. Second party could be a transportation company, or warehouse company to gain read access to the transaction date when needed to carry on the operations.

\section{B. Transaction flow of Prochain}

In order to make the transactions happen, the transaction data captured by Prochain will undergo a consensus algorithm before appends the new transaction (block) to the supply chain network (chain). The prerequisite is the node will verify the identity of the party that submits the transaction request.

From Fig. 8, farmer will submit a transaction request to be appended to the blockchain database. Prochain will authenticate the farmer before allowing the transaction data to undergo the consensus algorithm.

Once the transaction data is signed after the consensus algorithm, it will append to the blockchain database, and Prochain will notify and show the results to farmer. Processor who is also in the same blockchain network will query the transaction information when in need. Processor will still need to be authenticated before access the transaction data.

\section{Consumer}

Consumer is a special party in Prochain. The way consumer gains the read access of a product can be in several ways, i.e. QR code, barcode and RFID tag. It is up to the retailer or other relevant parties who sold the product to consumer on how those parties want to disclose the information of a product to the consumer. Hence, the consumer does not need to authenticate identity to get the product information.

Based on Fig. 9, consumers request transaction information via $\mathrm{QR}$ code, barcode or RFID tag that will generate query through Prochain application. There is no identity authentication in the process and transaction result will straight away present to the consumer. 


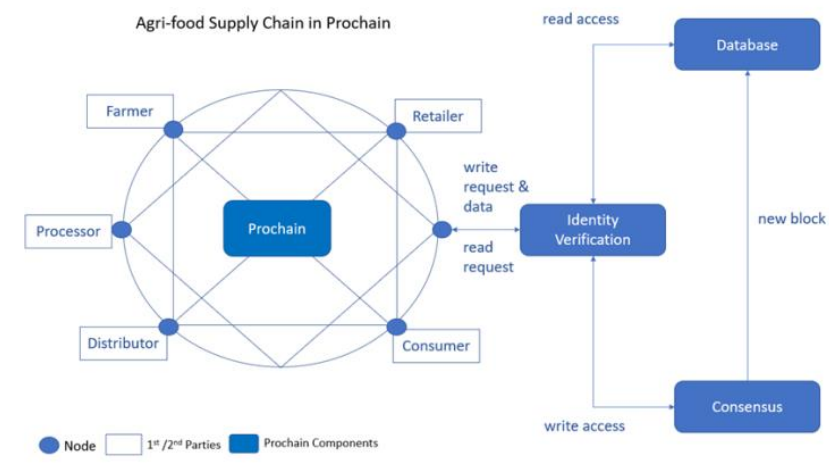

Fig. 7. Illustration of Conceptual Framework of Agri-food Supply Chain in Prochain.

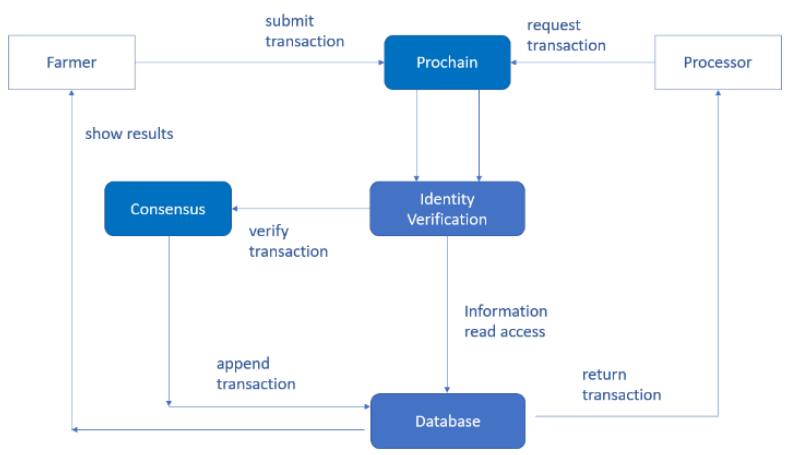

Fig. 8. Transaction Flow of from Farmer to Processor.

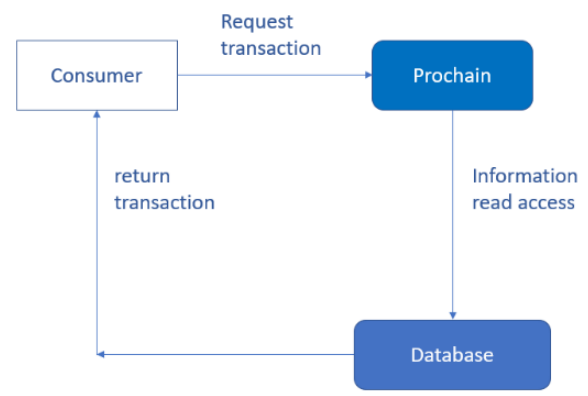

Fig. 9. Read Access of Consumer.

\section{Transparency and Traceability of Prochain}

In a centralized supply chain system, all the information is revolving from supply chain parties to the third-party layer service providers.

Fig. 10 depicts how are the parties in the supply chain manage the transactional data with each other via 3PL. There is a possibility that the data in such a system is mutable from other non-relevant parties that for suspicious purposes. Moreover, the third party like itself is having control over the data in the system where all the transactional data is supposed belong to the supply chain party. Hence the credibility of the data in the system has affected the transparency and traceability of the data.

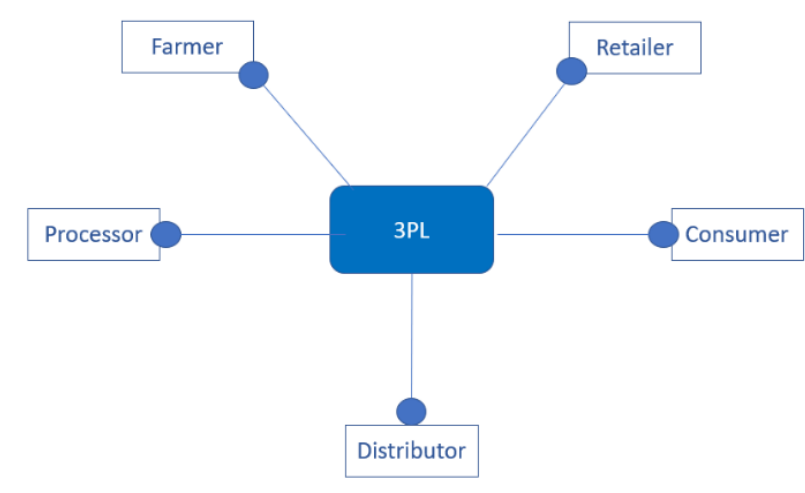

Fig. 10. Conceptual Framework for Centralized Supply Chain System.

Looking back the transaction flow of Prochain, none of the transaction has undergone to non-relevant party. The data in the blockchain is signed and encrypted by the default before appending to the blockchain database to ensure the credibility of the data. All the transaction flow is transparent among supply chain parties. Meanwhile the information in the blockchain data can be accessed in need to know basis. Hence it also maintained the confidentiality of the data. With the transparency of Prochain, the traceability of the system will work as it should be.

\section{IMPLEMENTATION AND ANALYSIS}

\section{A. Prochain Hyperledger Sawtooth Version}

Based on the transaction flow of conceptual framework as shown in Fig. 8, it depicts the general blockchain component interact with each other when a transaction is made. Fig. 11 presents a modified version of Prochain with Hyperledger Sawtooth blockchain applied.

Based on Fig. 11, farmer or processor can have read-write access via the Sawtooth client. Either one of the access will first notice the validator in the blockchain network. The validator will first examine the access right of the user, if the user is doing a transaction submission, the validator will communicate with the transaction processor which is the backend service of Sawtooth, if the transaction is valid it will undergo the PoET consensus for the creation of the new block.

Waiting time is randomly assigning to all the nodes (validators) that in charge of validating the transaction, regardless of the power or type of hardware of that node possesses. Then the validator with the shortest wait time will have to append the new block and update the global state, which is the database that consists of all and the latest record of the ledger and being shared across all nodes of that blockchain network.

\section{B. Prochain Hyperledger Fabric Version}

Things work differently in Hyperledger Fabric of blockchain as it has different components such as Membership Service Provider (MSP), the consensus algorithm and World State. 


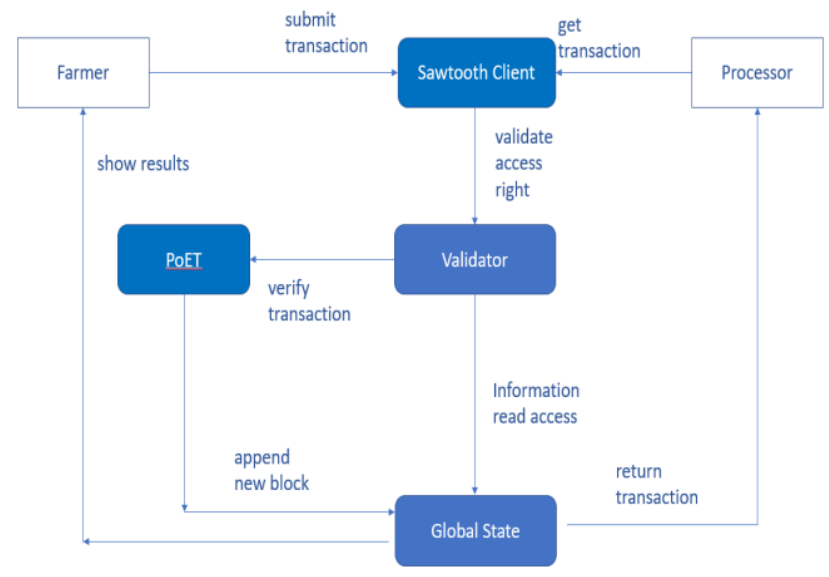

Fig. 11. Prochain Hyperledger Sawtooth Version

Based on Fig. 12, the user can have read write access via Fabric Client. The MSP will validate the access right of the user. If the user is submitting transaction it will pass to peers and undergo Kafka consensus algorithm before appending the new block. A much details visualization of the process is shown in Fig. 13.

The Peers in Fig. 12 consists of Endorsing Peer and Committing Peer. The role of Endorsing Peer is passing a set of transaction data that proposed by the user to be sorted under Kafka. There is a need of Kafka (an ordering mechanism) to sort out the set of transaction data then will pass to the Committing Peer that in charge of creating the new block into the World State. World state is a database that store all and the latest record of ledger that being shared across all nodes in that blockchain network.

\section{Transparency and Traceability of Fabric and Sawtooth}

Although the consensus algorithm of Hyperledger Sawtooth and Hyperledger Fabric are not the same, it will not have any impact on the transparency nor the traceability of Prochain, as it just affects the steps on approving the creation of the new block.

However, transparency and traceability of Prochain are affected by the variation of the building block of Sawtooth and Fabric. One notable of that variation is the feature of Channel provided from Fabric that allows the stakeholders in the network carry out transaction privately with a subset of other stakeholders that are not visible to another subset of stakeholders.

In Fig. 14, the data of transaction A is visible to Farmer A, Processor A and Distributor A as all of them are on the same channel. However, the data of transaction $\mathrm{B}$ is only visible among Farmer B and Processor A but not Farmer A and Distributor A, note that both channels co-exist in the same blockchain network.

Based on the steps of establishing the supply chain transparency and transparency in Fig. 3, a subset of data of suppliers (Farmer and Processor) and transaction data (pepper) is disclosed as shown in Fig. 15 under the agreement agreed among stakeholders in the supply chain network. Both the Sawtooth and Fabric version of Prochain is using the same data in the analysis.
Fig. 16 shows that Sawtooth can achieve 100 percent transparency and traceability whereas Fabric is a little bit more complicated. In the same channel of stakeholders, it can have the same results as Sawtooth, but stakeholder that is out of that channel has zero visibility of the data.

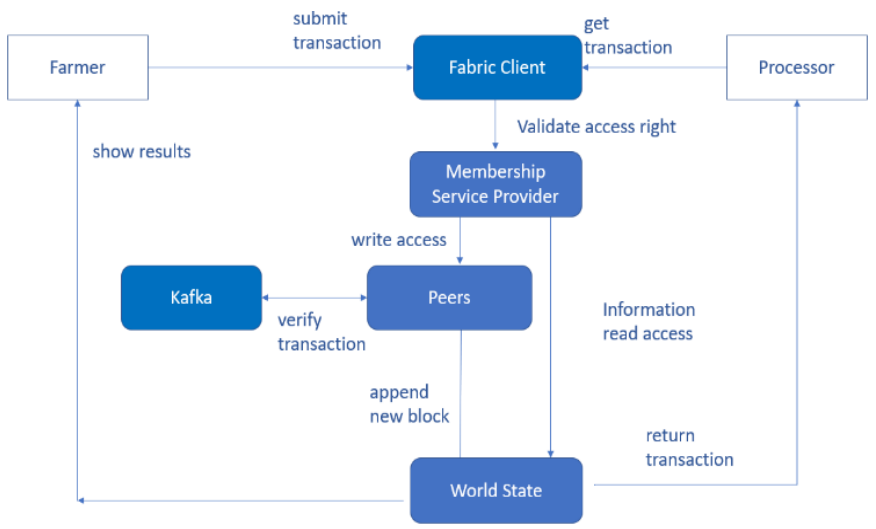

Fig. 12. Prochain Hyperledger Fabric Version.

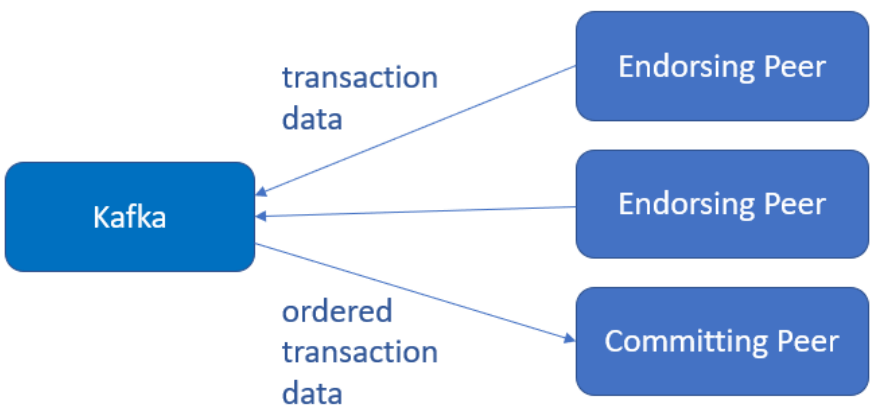

Fig. 13. Transaction flow in Ordering Service.

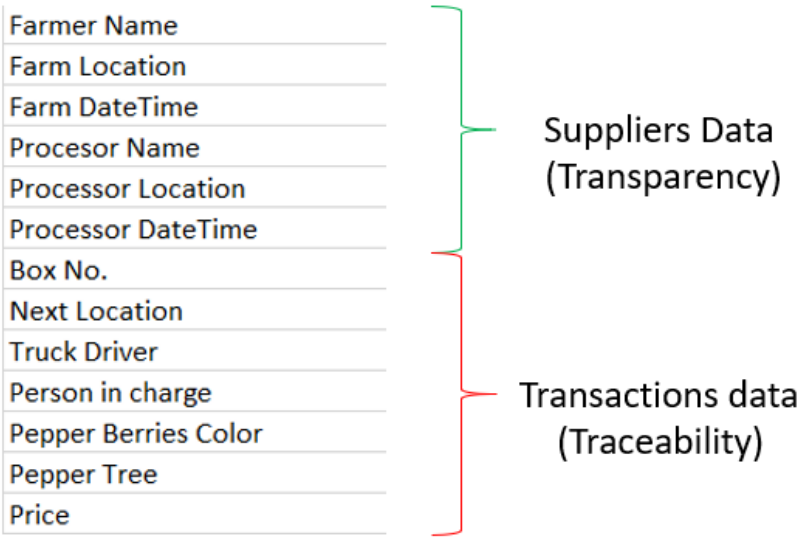

Fig. 14. 2 Channels in the Same Blockchain Network.

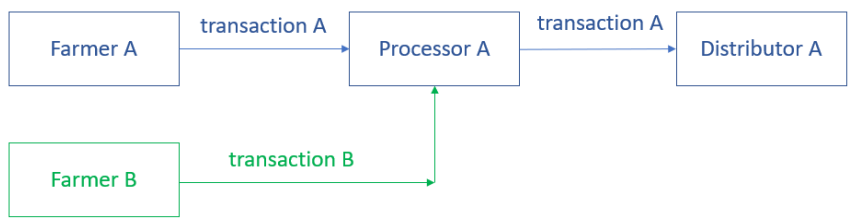

Fig. 15. Suppliers and Transactions Data from Farmer to Processor. 


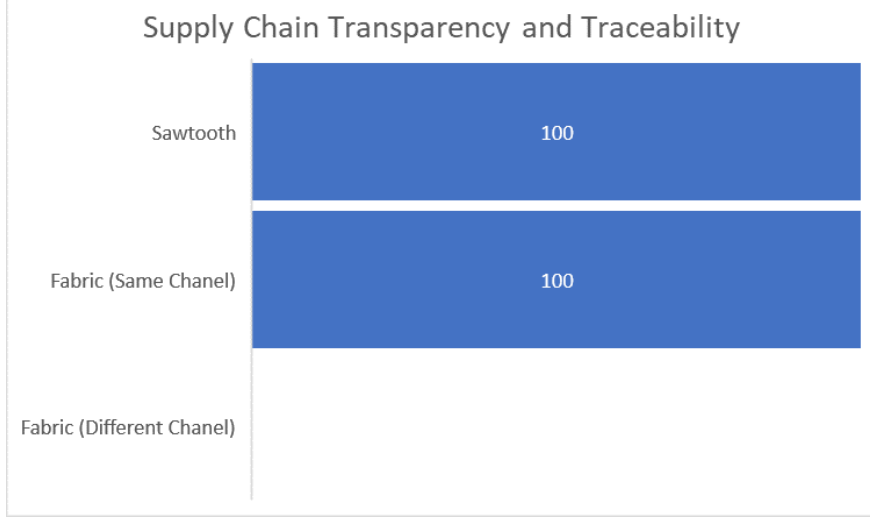

Fig. 16. Transparency and Traceability.

\section{CONCLUSION AND FUTURE WORK}

This study explained how permissioned blockchain a better fit in supply chain management is compared to a permissionless blockchain. Among the permissioned blockchain Hyperledger Sawtooth and Fabric, the framework of Sawtooth has a more technological conditions that inclined with to better transparency than Fabric due to the MSP feature makes it have more central control mechanism. However, there might exist some scenario where supply chain player might favor Fabric over Sawtooth if supplier value data privacy more than data transparency.

There is still much work to be done in this research. Prochain framework can further extend with other permissioned blockchain technology like Hyperledger Indy, Burrow or other non-Hyperledger blockchains such as Quorum.

\section{REFERENCES}

[1] R. B. Handfield and L. N. J. Ernest, in Supply Chain Redesign: Converting Your Supply Chain into an Integrated Value Stream, New York, Financial Prentice Hall, 2002.

[2] C. Hofstedel, H. Schepers, L. Spaans-Dijkstra, J. Trienekens and A. Beulens, in Hide or Confide: The Dilemma of Transparency, Gravenhage., Reed Business Information BV's, 2005.

[3] M. M. Aung and Y. S. Chang, "Traceability in a food supply chain: Safety and quality perspectives," Food Control, vol. 39, pp. 172-184, 2014.

[4] R. A. R. Manzini, "The new conceptual framework for food supply chain assessment," Journal of Food Engineering, vol. 115(2), pp. 251263, 2013

[5] M. Gupta, Blockchain For Dummies®, IBM Limited Edition, Hoboken, NJ: John Wiley \& Sons, Inc, 2017.

[6] A. Koo, A. L. Othman, P. Y. Moy and P. Khor, "Agribusiness," 2017. [Online]. Available: https://gettingthedealthrough.com/area/93/ jurisdiction/55/agribusiness-malaysia/.

[7] S. K. Mah, "Bright future for Sarawak pepper," 2017. [Online]. Available: Retrieved from https://www.thestar.com.my/news/nation/ 2017/10/25/malaysia-aims-to-be-worlds-top-supplier-of-the-premiumking-of-spices/.

[8] N. Fletcher, "llegal cross-border pepper, rubber farming uncovered," 2017. [Online]. Available: Retrieved from http://www.theborneopost. com/2017/04/03/illegal-cross-border-pepper-rubber-farming-uncovered/.

[9] R. Casado-Varaa, J. Prietoa, F. D. Prietaa and J. M. Corchado, "How blockchain improves the supply chain: case study alimentary supply chain," Procedia Computer Science, vol. 134, pp. 393-398, 2018.
[10] W. Yingli, H. Jeong Hugh and B.-D. Paul, "Understanding blockchain technology for future supply chains: a systematic literature review and research agenda," Supply Chain Management: An International Journal, vol. 24, no. 1, pp. 62-84, 2019.

[11] Chetak Logistics, "Difference between 1PL, 2PL, 3PL, 4PL \& 5PL," 2015. [Online]. Available: https://www.linkedin.com/pulse/differencebetween-1pl-2pl-3pl-4pl-5pl-chetak-logistics/.

[12] H. H. Lee, "How a "3-D" supply chain process system could revolutionize business," 2013. [Online]. Available: http://www. supplychainquarterly.com/topics/Strategy/20130621-how-a-3-d-supplychain-process-system-could-revolutionize-business/.

[13] ChainThat Limited. , "Simple introduction to smart contracts on a blockchain," 2015. [Online].

[14] J. Laney, "How Blockchain can revolutionise the Supply Chain," 2018. [Online]. Available: https://jameslaney.com/blockchain-revolutionisesupply-chain/.

[15] N. Egels-Zandén and N. Hansson, "Supply chain transparency as a consumer or corporate tool: The case of Nudie Jeans Co," Journal of Consumer Policy, vol. 39(4), pp. 377-395, 2015.

[16] G. A. Akerlof, "The market for "Lemons": Quality uncertainty and the market mechanism," Quarterly Journal of Economics, vol. 84(3), pp. 488-500, 1970.

[17] D. Tapscott and D. Ticoll, The naked corporation: How the age of transparency will revolutionize business, Free Press, 2003.

[18] T. Horst, "The impact of the blockchain on the supply chain: a theorybased research framework and a call for action," Supply Chain Management: An International Journal, vol. 23, no. 6, pp. 545-559, 2018.

[19] K. Tsai, "Transparency vs. Traceability: What's the Difference?," 2018. [Online]. Available: https://www.transparency-one.com/transparencyvs-traceability-whats-the-difference/.

[20] F. Casinoa, T. K, Dasaklisb and P. Constantinos, "A Systematic Literature Review of Blockchain-based Applications: Current Status,Classification and Open Issues," Telematics and Informatics, vol. 36, pp. 55-81, 2019.

[21] T. Surasak, N. Wattanavichean, C. Preuksakarn and S. C.-H. Huang, "Thai Agriculture Products Traceability System usingBlockchain and Internet of Things," International Journal of Advanced Computer Science and Applications, vol. 10, no. 9, pp. 578-583, 2019.

[22] A. Ahmad, J. Salman, K. Shah, A. Toqeer, A. Yazed and Y. Muhammad , "A Blockchain-based Value Added Tax (VAT)System: Saudi Arabia as a Use-Case," International Journal of Advanced Computer Science and Applications, vol. 10, no. 5, pp. 708-716, 2019.

[23] N. Tien Thanh Le, Q. Nghiep Nguyen, N. Ngoc Phien, N. Duong-Trung, T. Tam Huynh, T. Phuc Nguyen and H. Xuan Son, "Assuring Nonfraudulent Transactions in Cash onDelivery by Introducing Double Smart Contracts," International Journal of Advanced Computer Science and Applications, vol. 10, no. 5, pp. 677-684, 2019.

[24] Y. Sobia, K. Muhammad Murad, T. Ramzan, B. Arslan Dawood, S. Sohaib , A. Fatima and N. Amna , "Use of Blockchain in Healthcare: A SystematicLiterature Review," International Journal of Advanced Computer Science and Applications, vol. 10, no. 5, pp. 644-653, 2019.

[25] N. Duong-Trung, X. Son Ha, T. Tai Phan, P. Nam Trieu, Q. Nghiep Nguyen, D. Pham, T. Tam Huynh and H. Trieu Le, "Multi-Sessions Mechanism for Decentralized Cashon Delivery System," International Journal of Advanced Computer Science and Applications, vol. 10, no. 9, pp. 533-560, 2019.

[26] R. Asad , K. Muhammad Murad, T. Ramzan , B. Arslan Dawood, H. Noman, A. Sultan and R. Muhammad Razeen, "Use of Blockchain in Governance: A SystematicLiterature Review," International Journal of Advanced Computer Science and Applications, vol. 10, no. 5, pp. 685691, 2019.

[27] Hyperledger, "About Hyperledger," 2018. [Online]. Available: https://www.hyperledger.org/about. 